Gazi Üniversitesi
Fen Bilimleri Dergisi
PART C: TASARIM VE TEKNOLOJI
dergipark.gov.tr/http-gujsc-gazi-edu-tr

\title{
Elektro Erozyon ile İşlemede İşleme Haznesine Uygulanan Titreşimlerin Geometrik Elektrot Aşınması Üzerindeki Etkilerinin İncelenmesi
}

\author{
Ali ÖZGEDIK ${ }^{1, *}$ Sadık Mert BALCI ${ }^{2,}$ Muhammed Emin ERDINN ${ }^{3,}$ Yağmur KOPRAMAN ${ }^{4}$ \\ ${ }^{I}$ Gazi Üniversitesi, Teknoloji Fakültesi, İmalat Mühendisliği Bölümü, 06500, Teknikokullar/ANKARA \\ ${ }^{2} \dot{I}$ yon Havacılık ve İleri Imalat Limited Şirketi, Kâğ thane/İSTANBUL \\ ${ }^{3}$ Hitit Üniversitesi, Mühendislik Fakültesi, Makine Mühendisliği Bölümü, 19030, ÇORUM \\ ${ }^{4}$ Gazi Üniversitesi, Teknoloji Fakültesi, İnşaat Mühendisliği Bölümü, 06500, Teknikokullar/ANKARA
}

$\ddot{O} z$

Makale Bilgisi

Başvuru: 24/10/2017

Düzeltme: 28/10/2017

Kabul: 20/11/2017

Anahtar Kelimeler

Elektro erozyon ile işleme İsleme haznesi titreşimi Geometrik elektrot aşınmast

Keywords

Electrical discharge machining

Machining tank vibration Geometric wear of tool electrode
$\mathrm{Bu}$ çalışmada, Elektro Erozyon ile İşleme (EEI) tekniğinde işleme haznesine uygulanan titreşimlerin elektrot köşe aşınma geometrisi ve performans çıktıları üzerindeki etkilerinin incelenmesi için titreşim frekansı, boşalım akımı ve vurum süresi gibi farklı işleme koşullarında deneyler yapılmıştır. İşleme haznesi titreşimli (İHT-EEI) deneylerde titreşimsiz koşullara göre elektrot aşınma hızı (EAH) ve bağıl aşınma (BA) değerleri azalmıştır. Deneysel sonuçlara göre işleme haznesine uygulanan titreşimler elektrot köşe yarıçap değerlerinde azalmaya neden olmuştur.

An Investigation on the Effects of Vibrations Applied to the Machining Tank on Geometric Wear of Tool Electrode in Electrical Discharge Machining

\begin{abstract}
In this study, experiments are conducted with different machining conditions such as vibration frequency, discharge current and pulse duration to investigate the effects of vibrations applied to the machining tank on geometric corner wear of tool electrode and performance outputs in Electrical Discharge Machining. Tool wear rate (TWR) and relative wear (RW) are dropped at experiments with machining tank vibration (MTV-EDM), when compared to experiments without vibrations. According to the results of experiments, vibrations applied to the machining tank have caused a decrease in the values of electrode corner radius.
\end{abstract}

\section{GİRIŞ̧ (INTRODUCTION)}

Elektro-Erozyon İle İşleme (EEI) kalıp ve takım imalatında yaygın olarak kullanılan dielektrik bir sıvı içerisinde takım elektrot ve işparçası arasında oluşan elektriksel boşalımın işparçasını mikro boyutlarda aşındırması esasına dayanan alışılmamış bir imalat yöntemidir. (Şekil 1).

EEI'de işleme mekanizması elektriksel boşalımların işparçası malzemesini mikro boyutlarda ergitmesine ve buharlaştırmasına dayanır [1]. Bu süreç içerisinde elektrot malzemesinin de aynı termal koşullar nedeniyle aşındığı gözlenmektedir [2]. Bu durum EEİ tekniğinin en temel problemlerinden birisidir. Ayrıca dielektrik sıvının uygulanma şekline ve hızına bağlı olarak meydana gelebilecek bölgesel kirlilik işleme boşluğunda kısa devre tipi vurumların oluşmasına neden olmaktadır. Bunun sonucunda işparçası işleme hızı (IIIH) azalırken, elektrot aşınma hızı (EAH) ve bağıl aşınma (BA) artarak, işparçası yüzey düzgünlügü ve geometrisi olumsuz yönde etkilenir [2-4]. Elektrottaki hacimsel aşınmanın yanında işleme 
aralığındaki dielektrik sıvının bölgesel kirlenme, sıcaklık ve gaz oluşumu karakteristikleri elektrot yan yüzeyinde, köşelerinde ve ön yüzeylerinde geometrik aşınmanın farklılığına neden olmaktadır [5-6]. Elektrotta oluşan aşınma karakteristikleri işparçasını doğrudan etkilediği ve elektrot maliyetlerinin artmasına neden olduğu için elektrot aşınması EEİ ile işleme maliyetini belirleyici faktördür. $\mathrm{Bu}$ nedenlerden dolayı EEI işleminin planlanması esnasında, elektrotun hacimsel ve geometrik aşınma karakteristiklerinin göz önüne alınması gerekir.

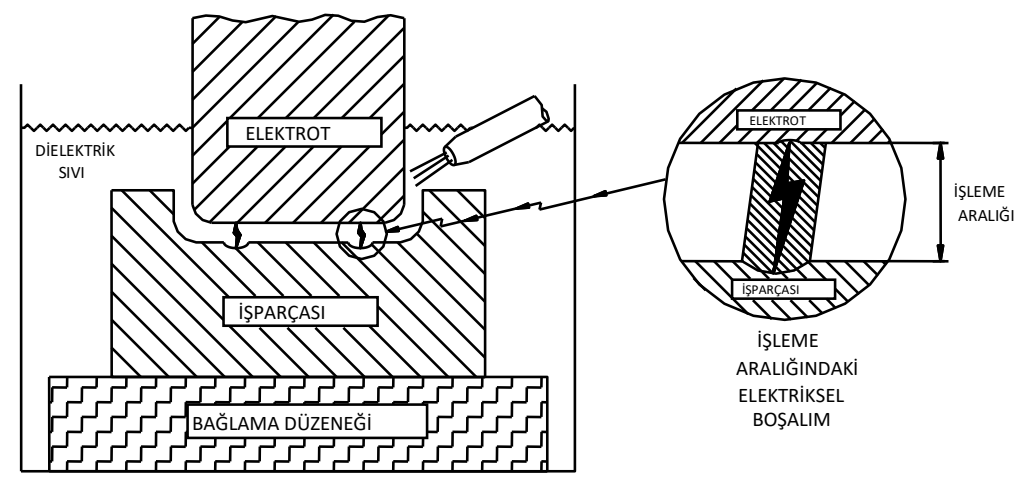

Şekil 1. EEI'nin şematik görünüşü

Elektrot aşınmasının klasik EEİ tekniği kullanılarak hem hacimsel hem de geometrik olarak incelendiği birçok çalışmaya literatür araştırması sonucunda ulaşılmıştır. Bunların genelinde [6-11] temel işleme parametrelerinin değişimine karşıllk işleme hızı ve hacimsel elektrot aşınmasındaki değişim incelenmiştir. $\mathrm{Bu}$ çalışmaların yanı sıra işleme parametrelerinin değişimine karşılık elektrot aşınmasının geometrik aşınma karakteristiğinin incelendiği çalışmalar da mevcuttur [4, 6, 9, 12-15]. Ayrıca EEİ ile işlemede performans çıktılarını iyileştirmek için EEİ ile işlemenin temel prensibi değiştirilmeden tezgah, elektrot ve işparçasına eklenen bazı donanımlar ile işparçası, elektrot, ve dielektrik sıvı elemanlarına dinamik hareketlilik kazandırılmıştır [16-22]. Yapılan bu modifikasyonların olumlu etkiler sağladığı tespit edilmiştir. Çalışma kapsamında yapılan literatür araştırması neticesinde performans çıtılarını iyileştirmek için işparçası veya elektroda kazandırılan dinamik hareketliliğin kullanıldığı deneysel çalışmalar içerisinde elektrodun geometrik aşınma karakteristiğinin incelendiği herhangi bir çalışma tespit edilememiştir.

EEİ işlemindeki elektrot aşınmasının daha iyi anlaşılabilmesi için EAH, BA ve elektrotta meydana gelen geometrik aşınmasının bir bütün olarak ele alınması gereklidir. Bu nedenle başka bir çalışmada [22] işparçasının bağlı olduğu işleme haznesine uygulanan farklı frekans değerine sahip titreşim koşulları ile yapılmış işleme deneylerinde elde edilen elektrot numuneleri kullanılarak elektrot aşınma hızının, bağıl aşınmanın ve silindirik elektrotta oluşan geometrik köşe aşınması bu çalışmada incelenmiştir.

\section{ELEKTRO-EROZYON ILE IŞLEMEDE ELEKTROT AŞINMASI (TOOL ELECTRODE WEAR in ELECTRICAL DISCHARGE MACHINING)}

EEİ ile işlemede işleme aralığında oluşan her bir elektriksel boşalım ile işparçası malzemesinden bir miktar talaş kaldırılırken elektrot malzemesinde de belirli bir miktarda malzeme aşınır. Elektrot malzemesinde meydana gelen bu aşınma Elektrot Aşıımma Hızı (EAH), Bağıl Aşınma (BA) ve geometrik aşınma başılıları altında incelenebilir. EAH ve BA terimleri aşağıdaki eşitlikler ile açıklanabilir.

Elektrot Aşınma Hızı (EAH) [mm3/dak] = elektrottan aşınan hacim / işleme süresi

İşparçası işleme hızı (İ̈H) [mm3/dak] = işparçasından işlenen hacim / işleme süresi

Bağıl Aşınma (BA) [\%] = (EAH / İ̈H )x100 
EEİ ile işlemede elektrot üzerinde oluşan geometrik aşınma ise yan yüzey aşınması, köșe aşınması ve ön yüzey aşınması başlıkları altında incelenebilir (Şekil 2) [6]. Bu çalışmada EAH ve BA karakteristiklerine ek olarak EEİ ile işleme sırasında akım yoğunluğunun daha fazla olduğu elektrotların keskin köşelerinde işlemenin başlamasıyla birlikte çok hızlı bir şekilde meydana gelen köşe aşınması incelenecektir (Şekil 2). Bu aşınma Şekil 2'de gösterildiği gibi köşelerin yuvarlanması şeklindedir.

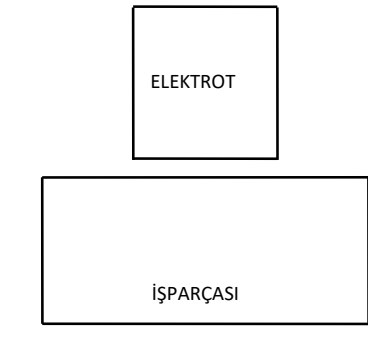

a) İsleme Öncesi

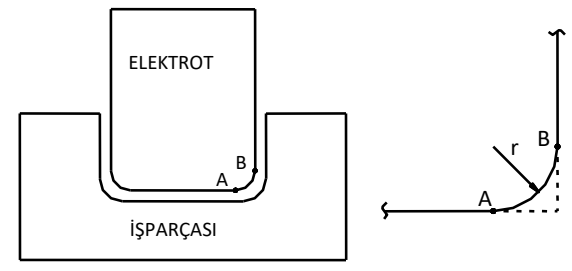

b) İsleme Sonrası

Şekil 2. Elektrot köşe aşınması

\section{DENEY DÜZENEĞİ, NUMUNELER ve DENEY PARAMETRELERİ (EXPERIMENTAL SETUP, SPECIMENS and EXPERIMENTAL PARAMETERS)}

Bu çalışmada kullanılan numuneler başka bir çalışmada [22] işparçasının bağlı olduğu işleme haznesine uygulanan farklı frekans değerine sahip titreşim koşulları ile yapılmış işleme deneylerinde elde edilmiş numunelerdir.

\subsection{Deney Düzeneği (Experimental Setup)}

Furkan marka elektro erozyon tezgahının ve 196 N 'luk sarsıcının kullanıldığg deney düzeneğinde (Şekil 3) gazyağı dielektrik sıvı ortam içerisinde titreşimli ve titreşimsiz koşullarda deneyler gerçekleştirilmiştir [22].

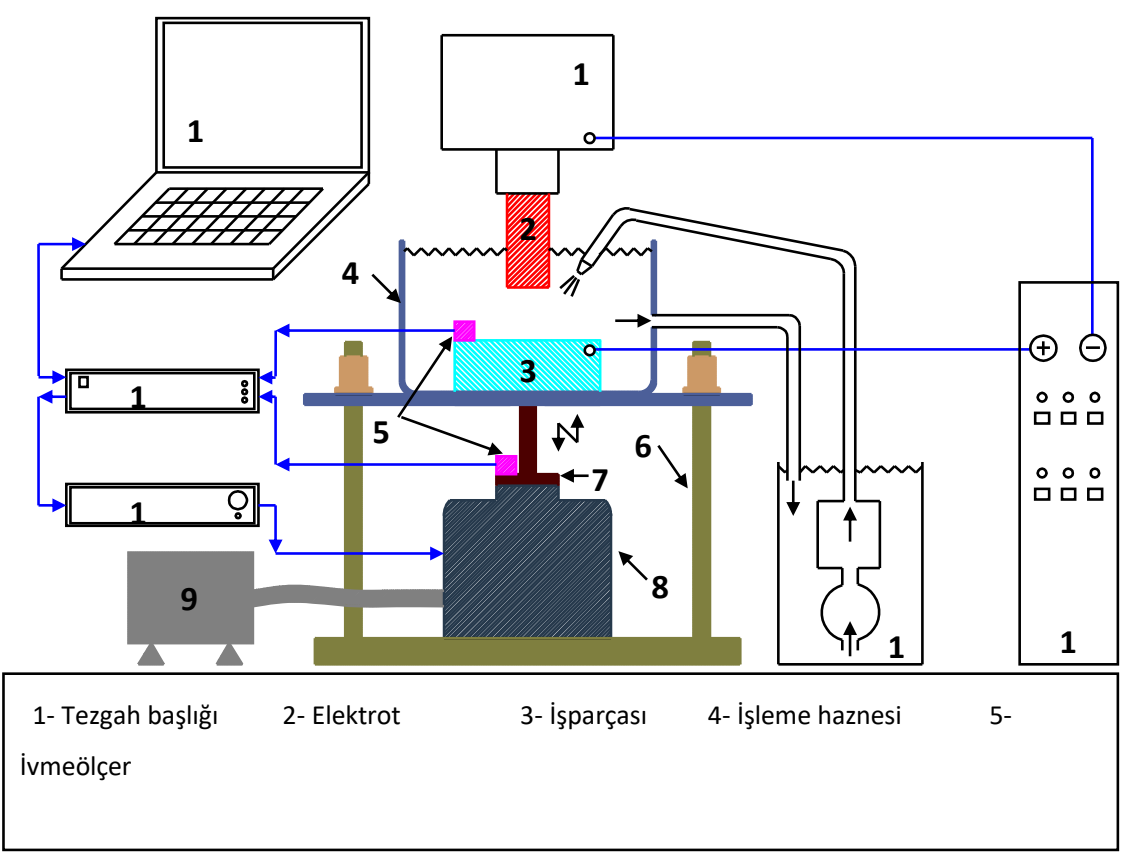

Şekil 3. IHHT-EEİ tekniği şematik görünümü 


\subsection{Numuneler (Specimens)}

Deneylerde kullanılan Ç1040 işparçası ve elektrolitik bakır malzemeye ait boyutlar Şekil 4' de verilmiştir [22].
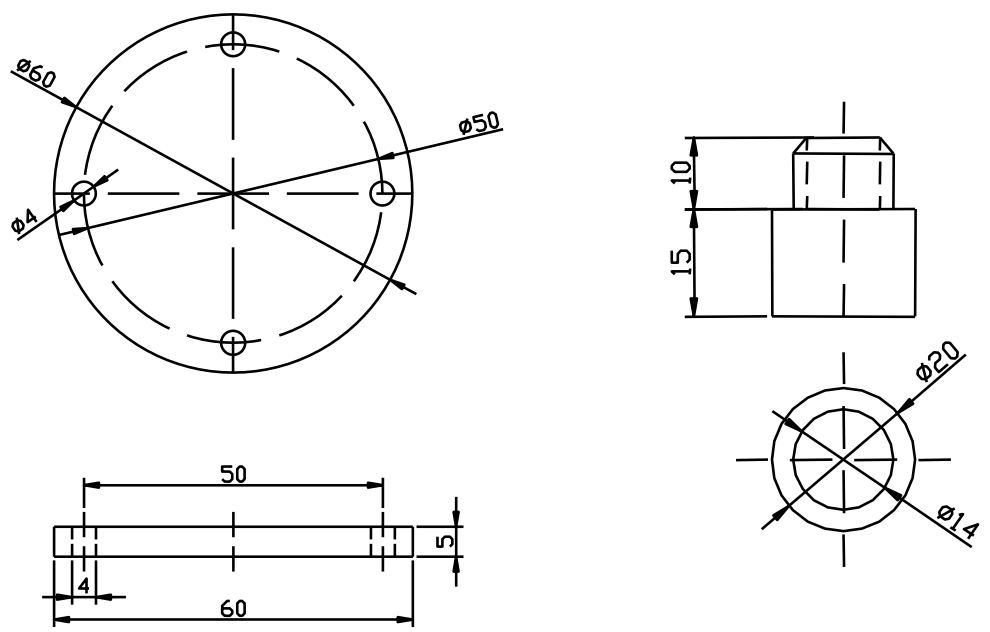

Şekil 4. Işsparçası ve elektrot ölçüleri

\subsection{Deney Parametreleri (Experımental Parameters)}

Deneylerde kullanılan değişen ve sabit parametreler Tablo 1'de verilmiş̧ir. Değiş̧en parametrelere bağlı olarak Tablo 2'de görülen 9 adet set için deneyler yapılmıştır [22].

Tablo 1. Deney parametreleri

\begin{tabular}{|l|l|}
\hline Deney Parametreleri & Değerler \\
\hline Boşalım Akımı $\left(i_{d}\right)[A]$ & 6,12 \\
\hline Vurum Süresi $\left(t_{s}\right)[\mu \mathrm{s}]$ & 100,200 \\
\hline Titreşim frekansı $\left(f_{v}\right)[\mathrm{Hz}]$ & $0,500,1000$ \\
\hline Bekleme Süresi $\left(t_{p}\right)[\mu \mathrm{s}]$ & 50 \\
\hline İşleme süresi $\left(t_{m}\right)[$ dak. $]$ & 30 \\
\hline Dielektrik sıvı & Gazyağı \\
\hline Dielektrik sıvı pompa basıncı $(\mathrm{P})[$ bar $]$ & 0,5 \\
\hline Kutuplama & Elektrot $(+)$, İşparçası $(-)$ \\
\hline
\end{tabular}

Tablo 2. Deney seti tasarımı

\begin{tabular}{|c|c|c|}
\hline $\begin{array}{c}\text { Boşalım Akımı } \\
\left(i_{d}\right)[A]\end{array}$ & $\begin{array}{c}\text { Vurum Süresi } \\
\left(t_{s}\right)[\mu \mathrm{s}]\end{array}$ & $\begin{array}{c}\text { Titreşim Frekans1 } \\
\left(\mathrm{f}_{\mathrm{v}}\right)[\mathrm{Hz}]\end{array}$ \\
\hline 6 & 100 & $0,500,1000$ \\
\hline 6 & 200 & $0,500,1000$ \\
\hline 12 & 200 & $0,500,1000$ \\
\hline
\end{tabular}




\section{4. ÖLÇÜMLER (MEASUREMENT)}

\section{1. İşparçası İşleme Hızının (İïH) ve Elektrot Aşınma Hızının (EAH) Tespiti (Determination of Workpiece Removal Rate and Tool Wear Rate)}

İşparçaları ve elektrotlar işleme öncesi ve sonrası $0,001 \mathrm{gr}$ hassasiyete sahip dijital terazi ile tartılmış ve yoğunluk değerleri kullanılarak hacimsel aşınma miktarı hesaplanmıştır. Hacimsel aşınma işleme süresine bölünerek İIH $\left[\mathrm{mm}^{3} / \mathrm{dak}\right]$ ve EAH $\left[\mathrm{mm}^{3} /\right.$ dak] hesaplanmıştır [22].

\subsection{Geometrik Elektrot Aşınmanın Tespiti (Determination of Geometrical Electrode Wear)}

Elektrot numunelerin işleme sonrasındaki kesme işlemi tel erozyon tezgahı ile Şekil 5'deki aparat kullanılarak gerçekleştirilmiştir.

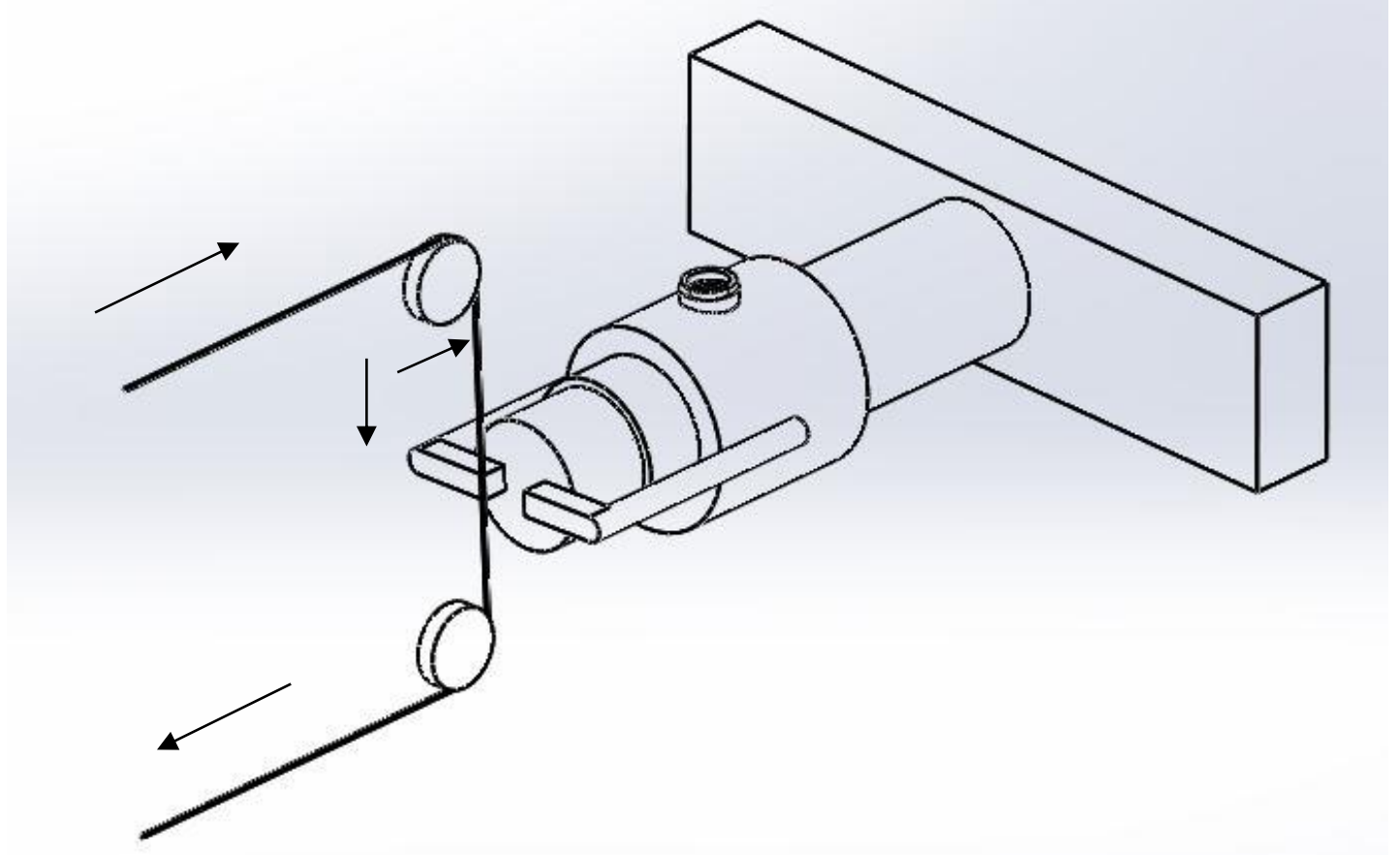

Şekil 5. Elektrodun kesilme işlemi

Kesme işlemi sonrası numune kesitlerinin bir yarısı tarayıcı ile 1200 dpi çözünürlükte taranmıştır. Kesit köşelerinde oluşan aşınma profiline ait koordinat verileri GetData Graph Digitizer görüntü işleme programı kullanılarak elde edilmiştir (Şekil 6 ve Şekil 7). Elde edilen dairesel yay parçasına ait veriler Matlab programında işlenerek geometrik köşe aşınmasına ait yarıçap değerleri elde edilmiştir. 


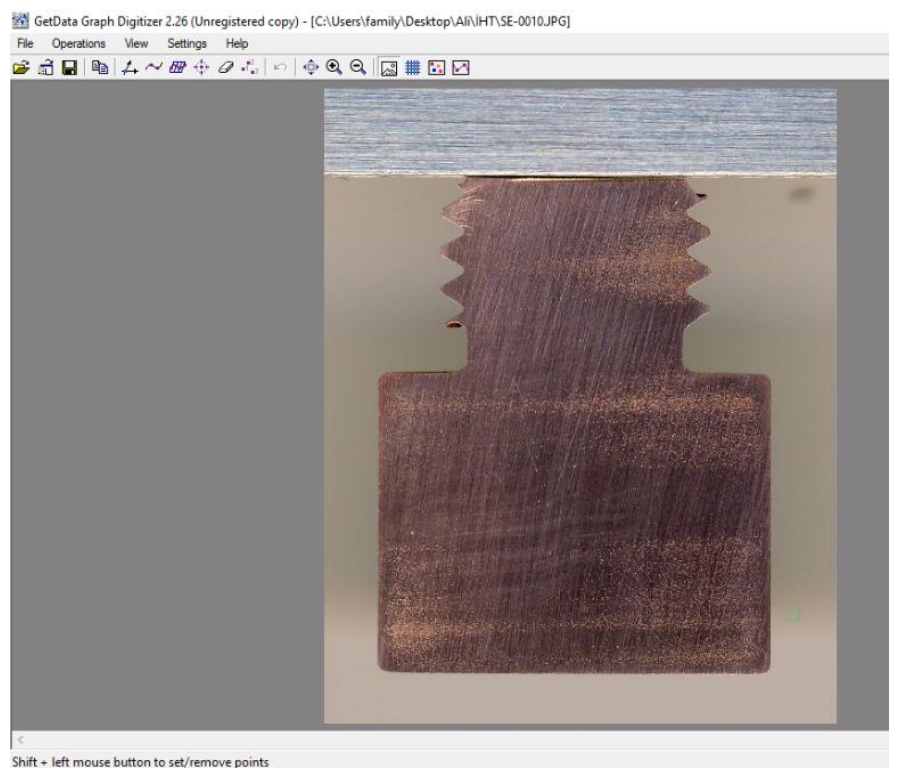

Şekil 6. Elektrot kesit görüntüsü

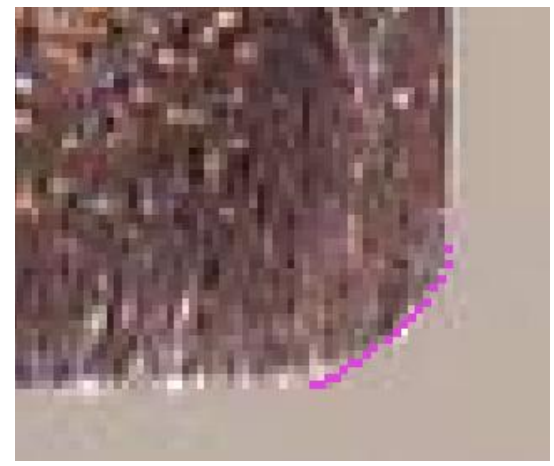

Şekil 7. Köşe profili koordinat tespit görüntüsü

\section{DENEY SONUÇLARI (EXPERIMENTAL RESULTS)}

\subsection{Uygulanan Titreşimin Elektrot Aşınma Hızına (EAH) Etkisi (The Effect of Applied Vibration on Tool Wear Rate)}

İşleme haznesine uygulanan titreşimler $6 \mathrm{~A}-100 \mu \mathrm{s}$ koşulunda elektrot aşınma hızı değerlerinde \%1-2

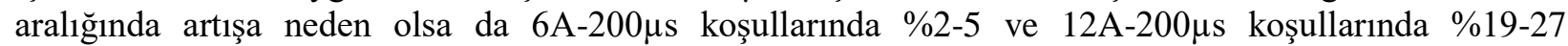
aralığında azalmaya neden olmuştur (Şekil 8). Sonuçlar uygulanan titreşimlerin EAH değerleri üzerindeki beklenen olumlu etkisinin nispeten yüksek akım ve yüksek vurum süresi değerlerinde elde edildiğini göstermektedir. Ayrıca titreşim frekansının $500 \mathrm{~Hz}$ değerinden $1000 \mathrm{~Hz}$ değerine artışına bağlı olarak 6A$200 \mu$ s ve $12 \mathrm{~A}-200 \mu$ s koşulları için EAH değerleri sırasıyla \%2,3 ve \%9,3 azalma sergilemiştir. Bu durum yüksek akım seviyelerinde ve yüksek vurum süresi değerlerinde EAH değerleri açısından titreşimin daha faydalı olduğunu göstermiştir. EAH değerlerindeki bu olumlu etki daha uzun süreli vurumlarla daha çok sayıda eşleşen titreşim hareketinin daha fazla sirkülasyon hareketine neden olması ile açıklanabilir. 


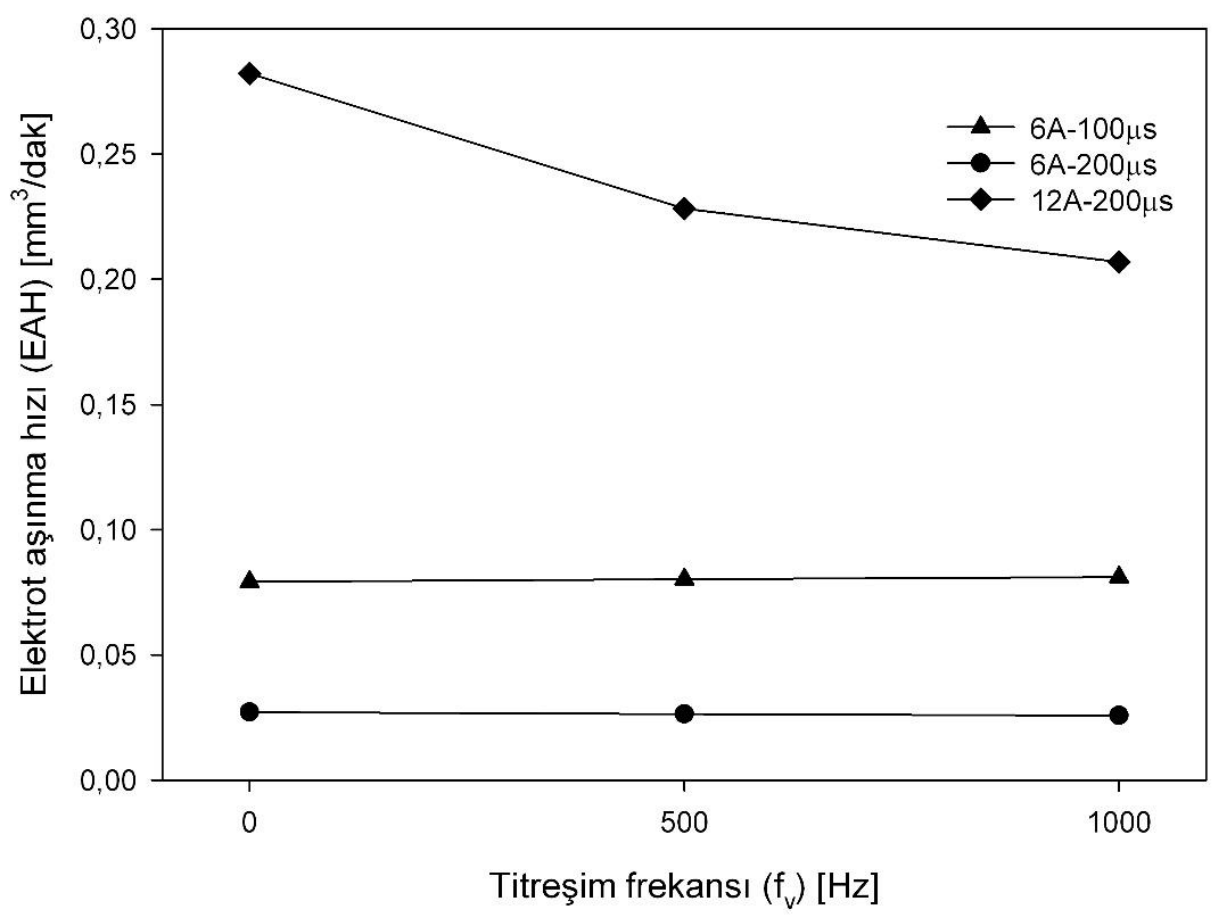

Şekil 8. Titreşimin elektrot aşınma hızına etkisi

\subsection{Uygulanan Titreşimin Bağıl Aşınmaya (BA) Etkisi (The Effect of Applied Vibration on Relative Wear)}

İşparçası işleme hızı değerlerinin titreşim uygulanan deneylerde azda olsa artışı ve elektrot aşınma hızı değerlerinin titreşimsiz koşullara göre azalmasıyla birlikte bağıl aşınma (BA) değerleri bütün titreşimli

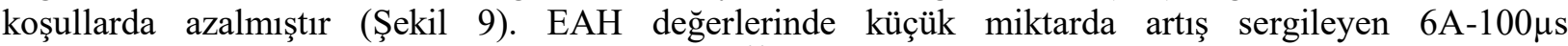
koşullarındaki titreşimli deneylerde BA değerleri İïH değerlerinin artışına bağlı olarak \%0,2-2 aralığında azalma sergilemiştir. EAH değerlerinin titreşimsiz koşullara göre azalma eğilimine sahip olduğu 6A$200 \mu \mathrm{s}$ ve $12 \mathrm{~A}-200 \mu$ s koşullarında ise uygulana titreşimler BA değerlerinde sırasıyla \%2-4 ve \%15-23 oranlarında azalmaya neden olmuştur. Titreşim frekansının $500 \mathrm{~Hz}$ değerinden $1000 \mathrm{~Hz}$ değerine artışına bağlı olarak $6 \mathrm{~A}-100 \mu \mathrm{s}, 6 \mathrm{~A}-200 \mu \mathrm{s}$ ve $12 \mathrm{~A}-200 \mu \mathrm{s}$ koşulları için BA değerleri sırasıly \% $\% 1,8, \% 2,1$ ve \%9,4 azalma sergilemiştir. Bu sonuçlar artan titreşim frekansının EAH değerleri üzerindeki olumlu etkisi ile uyum içerisindedir. 


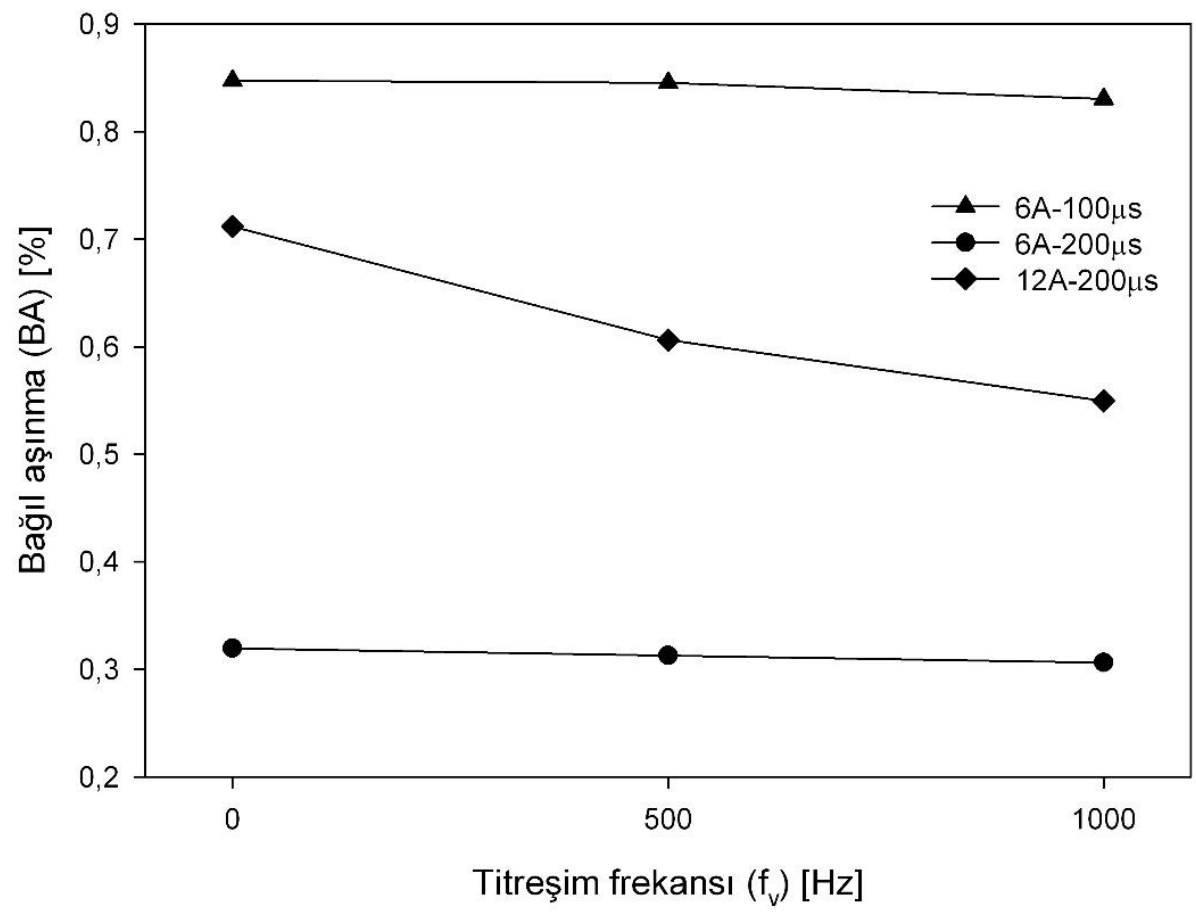

Şekil 9. Titreşimin bağıl aşınmaya etkisi

\subsection{Uygulanan Titreşimin Elektrot Köşe Yarıçap Değerine (r) Etkisi (The Effect of Applied Vibration on the Value of Corner Radius of Electrode)}

Bütün işleme koşulları için titreşimli deneylerde elektrot köşe yarıçap değerlerinin azalması uygulanan titreşimlerin işleme performans çıktıları üzerindeki en olumlu etkisi olarak ortaya çıkmıştır. İşleme

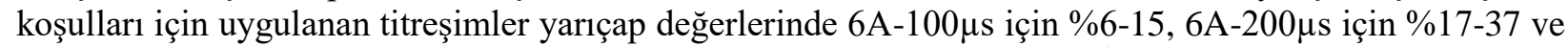
12A-200 $\mu$ s için \%24-38 oranlarında azalmaya neden olmuştur (Şekil 10). İşleme koşullarının tamamı için titreşimli deneylerde elde edilen köşe yarıçap değerlerinin titreşimsiz koşullara göre küçük çıkması işleme haznesine uygulanan titreşimlerin işleme ortamındaki dielektrik sıvı sirkülasyonunu daha etkili bir hale getirdiğini göstermektedir. İşleme ortamında oluşturulan etkili bir sirkülasyon hem işleme atıklarının ortamdan uzaklaştırılmasını nispeten daha iyi sağlayarak kısa devre tipi vurumların engellenmesi ile elektrot aşınmasını azaltmış hem de elektrotta akım yoğunluğuna bağlı olarak meydana gelen 1sınmayı azaltarak keskin köşelerdeki aşınma eğilimini azaltmıştır. Uygulanan titreşimlerin vurum süresi ve akım değerlerinin artışına bağlı olarak sergilediği bu olumlu etkisi $6 \mathrm{~A}-100 \mu \mathrm{s}$ ile $6 \mathrm{~A}-200 \mu \mathrm{s}$ ve $6 \mathrm{~A}-200 \mu$ s ile $12 \mathrm{~A}-200 \mu$ s koşullarında elde edilen köşe yarıçap değerlerindeki azalma oranları kıyaslandığında daha net olarak tespit edilmiştir.

EAH değerlerinin daha yüksek olduğu $12 \mathrm{~A}-200 \mu$ s koşulları için titreşimli ve titreşimsiz deneylerde elde edilen yarıçap değerleri $6 \mathrm{~A}-100 \mu \mathrm{s}$ ve $6 \mathrm{~A}-200 \mu$ s koşullarında elde edilen sonuçlara göre yaklaşı $\% 50$ oranında daha yüksek çıkmıştır. Bu durum yüksek akım değerlerinin uzun süreli uygulandığı koşullarda elektrotta meydana gelen akım yoğunluğuna bağlı olarak keskin köşelerdeki aşınma eğiliminin artış1 ile

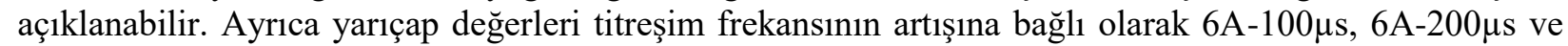
$12 \mathrm{~A}-200 \mu \mathrm{s}$ koşulları için sırasıyla $\% 10, \% 24$ ve $\% 20$ oranlarında azalmıştır. Bu durum aynı vurum süresine karşılık gelen titreşim hareketi sayısının artışının EAH ve BA değerlerindeki olumlu etkisi ile örtüşmektedir. 


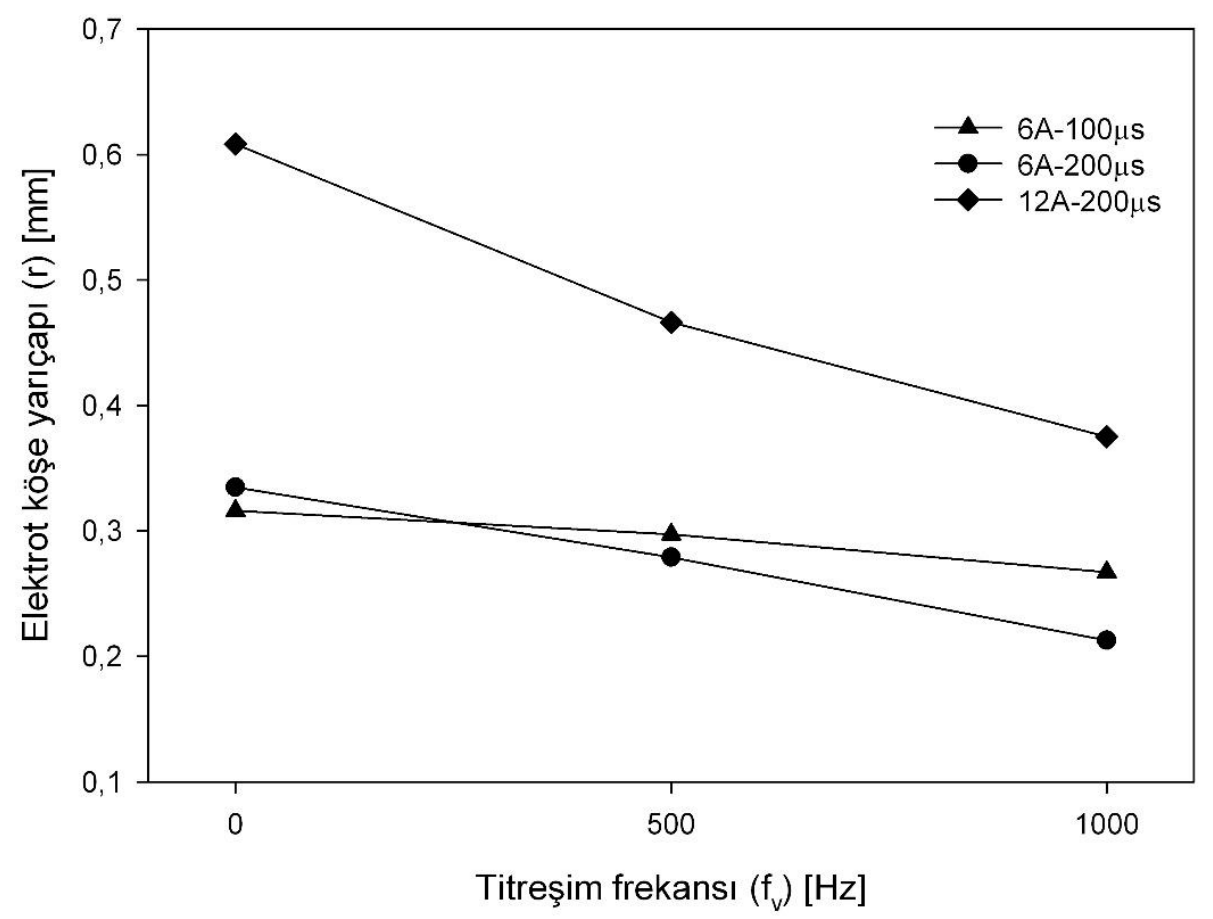

Şekil 10. Titreşimin köşe yarıçapına etkisi

\section{SONUÇLAR (CONCLUSIONS)}

Elektro Erozyon ile İşleme (EEİ) tekniğinde işlemenin gerçekleştiği hazneye bağlı sarsıcı ünite ile uygulanan farklı frekans $(500 \mathrm{~Hz}-1000 \mathrm{~Hz})$ değerlerindeki titreşimlerin titreşimsiz koşullara elektrot köşe aşınma geometrisi ve performans çıktıları üzerindeki etkileri incelenmiştir.

Deneysel sonuçlara göre titreşimli koşullarda titreşimsiz koşullara göre elektrot aşınma hızı değerlerinde $6 \mathrm{~A}-100 \mu \mathrm{s}$ koşulunda küçük bir oranda artış olurken $6 \mathrm{~A}-200 \mu \mathrm{s}$ ve $12 \mathrm{~A}-200 \mu \mathrm{s}$ koşulları için \%2-27 aralığındaki oranlarda azalma elde edilmiştir. Ayrıca titreşim frekansının artışı aynı koşullar için EAH değerlerinde \%2,3-9,3 aralığında azalmaya neden olmuştur. Bu durum işleme haznesine uygulanan titreşimlerin uzun vurum süresine ve yüksek akım değerlerine sahip deneylerde EAH değerlerinde daha etkili olduğunu göstermiştir.

İşparçası işleme hızı değerlerinde azda olsa meydana gelen artışa ve elektrot aşınma hızı değerlerindeki genel azalma eğilimine bağlı olarak bağıl aşınma değerleri bütün titreşimli koşullarda azalmıştır. BA değerleri titreşimsiz koşullara göre bütün deney parametreleri için \%0,2-23 aralığındaki oranlarda azalmıştır. Titreşim frekansının bütün koşullarda $500 \mathrm{~Hz}$ değerinden $1000 \mathrm{~Hz}$ değerine artışına bağlı olarak BA değerleri \%1,8-9,4 aralığında azalmıştır.

İşleme haznesine uygulanan titreşimlerin en olumlu etkisi bütün işleme koşulları için titreşimli deneylerde elektrot köşe yarıçap değerlerinin azalması olarak ortaya çıkmıştır. Titreşimli deneylerde yarıçap değerleri \%6-38 aralığındaki oranlarda azalmıştır. Bu durum uygulanan titreşimlerin işleme ortamındaki dielektrik sıvı sirkülasyonunu daha etkili bir hale getirerek işleme atıklarının ortamdan uzaklaştııılmasını kolaylaştırdığı ve kısa devre tipi vurumları engelleyerek elektrot aşınmasını azalttığını göstermiştir. Yarıçap değerleri titreşim frekansının artışına bağlı olarak bütün koşullarda \%10-24 aralığındaki oranlarda azalmıştır. 
Elde edilen sonuçlar genel olarak incelendiğinde işleme haznesine uygulanan titreşimlerin titreşimsiz koşullara göre EAH, BA ve köşe yarıçap değerlerinde azalmaya neden olduğu tespit edilmiştir. Bu olumlu etkinin özellikle yüksek akım ve vurum süresi değerlerinde ortaya çıktığı gözlemlenmiştir. Ayrıca frekans değerinin artışı bütün deney koşulları için EAH, BA ve köşe yarıçap değerlerinde azalmaya neden olmuştur. Artan vurum süresine karşılık daha çok sayıda titreşim hareketinin etkili sirkülasyon sağlaması sonucunda $\mathrm{EAH}, \mathrm{BA}$ ve köşe yarıçap değerlerinde azalma elde edileceği ve titreşim uygulamalarının yüksek akım değerlerinde daha etkili olacağı çalışmada elde edilen genel bir sonuçtur.

\section{KAYNAKLAR (REFERENCES)}

[1] S.L. Chen, B.H. Yan, F.Y. Huang, Influence of kerosene and distilled water as dielectrics on the electric discharge machining characteristics of Ti-6Al-4V, Journal of Materials Processing Technology, 87: 1-3 (1999) 107-111.

[2] T. Masuzawa, C.J. Heuvelman, A self flushing method with spark erosion machining, Annals of the CIRP, 32: 1 (1983) 109-111.

[3] B. M. Schumacher, About the role of debris in the gap during electrical discharge machining, Annals of the CIRP, 39: 1 (1990) 197-199.

[4] A. Özgedik, C. Çogun, An experimental investigation of tool wear in electric discharge machining, The International Journal of Advanced Manufacturing Technology, 27: 5-6 (2006) 488-500.

[5] J.R. Crookall, A theory of planar electrode face wear in EDM, Annals of the CIRP, 28: 1 (1979) 125-129.

[6] C. Çoğun, Ş. Akaslan, The effect of machining parameters on tool electrode wear and machining performance in electric discharge machining, KSME International Journal, 16: 1 (2002) 46-59.

[7] C. Çoğun, O. Poyrazoğlu, The variation of machining performance with machining parameters in EDM, 2nd International Conference on Design and Production of Dies and Molds, Kuşadas1, 2001.

[8] Y. Chen, S.M. Mahdavian, Parametric study into erosion wear in a computer numerical controlled electro-discharge machining process, Wear, 236 (1999) 350-354.

[9] N. Mohri, M. Suzuki, M. Furuya, N. Saito, Electrode wear process in electrical discharge machining, Annals of the CIRP, 44: 1 (1995) 165-168.

[10] S.L. Chen, B.H. Yan, F.Y. Huang, Influence of kerosene and distilled water as dielectrics on the electric discharge machining characteristics of Ti-6Al-4V, Journal of Materials Processing Technology, 87 (1999) 107-111.

[11] J.P. Kruth, L. Stevens, L. Froyen, B. Lauwers, Study of the white layer of a surface machined by die-sinking electro-discharge machining, Annals of the CIRP, 44: 1 (1995) 169-172.

[12] J.R. Crookall, R.J. Fereday, An experimental determination of the degeneration of electrode shape in EDM, Microtecnic, 17: 4 (1973) 197-200.

[13] J.R. Crookall, R.J. Fereday, An experimental determination of the degeneration of electrode shape in EDM, Microtecnic, 17: 2 (1973) 97-99.

[14] J. Pei, L. Zhang, J. Du, X. Zhuang, Z. Zhou, S. Wu, Y. Zhu, A model of tool wear in electrical discharge machining process based on electromagnetic theory, International Journal of Machine Tools and Manufacture, 117 (2017) 31-41. 
[15] K. Yaman, C. Çoğun, An experimental work on using conductive powder-filled polymer composite cast material as tool electrode in EDM, The International Journal of Advanced Manufacturing Technology, 73 (2014) 535-543.

[16] D.J. Kim, S.M. Yi, Y.S. Lee, C.N. Chu, Straight hole micro EDM with a cylindrical tool using a variable capacitance method accompanied by ultrasonic vibration, Journal of Micromechanics and Microengineering, 16: 5 (2006) 1092-1097.

[17] J. Zhixin, Z. Jianhua, A. Xing, Ultrasonic vibration pulse electro-discharge machining of holes in engineering ceramics, Journal of Materials Processing Technology, 53: 3-4 (1995) 811-816.

[18] J. Zhixin, A. Xing, Z. Jianhua, A. Zhaoliang, Combined machining of USM and EDM for advanced ceramics, Journal of Advanced Materials, 26: 3 (1995) 16-20.

[19] T. Hao, W. Yang, L. Yong, Vibration-assisted servo scanning 3D micro EDM, Journal of Micromechanics and Microengineering, 18: 2 (2008) 1-8.

[20] V.S.R. Murti, P.K. Philip, Pulse train analysis in ultrasonic assisted EDM, International Journal of Machine Tools and Manufacture, 27: 4 (1987) 469-477.

[21] M.M. Sundaram, G.B. Pavalarajan, K.P. Rajurkar, Study on process parameters of ultrasonic assisted micro EDM based on taguchi method, Journal of Materials Engineering and Performance, $17: 2$ (2008) 210-215.

[22] A. Özgedik, C. Çoğun, Elektro-Erozyon İle İşlemede İşleme Haznesine Uygulanan Titreşimlerin İşleme Performansına Etkilerinin İncelenmesi, Makine Teknolojileri Elektronik Dergisi, 8: 3 (2011) 13-25. 